\title{
Combining Ability of Husk Extension, Maysin Content, and Corn Earworm Resistance
}

\author{
Virginia M. Moore and William F. Tracy \\ Department of Agronomy, University of Wisconsin-Madison, 1575 Linden Drive, Madison, WI 53706
}

\begin{abstract}
Additional Index words. Helicoverpa zea, insect resistance, organic production, plant breeding, sweet corn, Zea mays
Abstract. Corn earworm (Helicoverpa zea) is a destructive pest with limited management options in sweet corn (Zea mays) production. Increased husk extension and the presence of the $\mathrm{C}$-glycosyl flavone maysin are two proposed mechanisms for improving corn earworm resistance in corn cultivars. A factorial mating design was conducted to test hybrid combinations of sweet corn inbreds with long husks and/or maysin to identify candidates for future cultivar development. The mating design had seven male parents, including three commercial sweet corn inbreds (Wh9261, We11401, and Wt1001) and four inbreds selected for maysin content (Maysin1, 2, 3, and 4), and five female parents, including two commercial sweet corn inbreds (Ia453su and Ia5125su) and three inbreds with long, thick, tight husks (A684su, A685su, and A686su). Hybrids were evaluated for ear length, husk length, maysin content, and corn earworm resistance at six environments in 2016 and 2017. Relationships between husk extension, maysin, and corn earworm resistance were inconsistent, but five inbreds produced hybrids with significantly lower corn earworm infestation and/or damage, demonstrating potential to confer resistance to the corn earworm.
\end{abstract}

Corn earworm (Helicoverpa zea) is the most destructive pest of sweet corn (Zea mays) (Del Valle and Miller, 1963; Pimentel et al., 1997; Snyder, 1967; Yadav, 1980). It is challenging to manage due to its migratory nature, its status as a generalist feeder (Hardwick, 1965; Huang, 2015; Kennedy and Storer, 2000; Neunzig, 1963; Olmstead et al., 2016; Sudbrink and Grant, 1995), and its oviposition and feeding habits (Barber, 1941; Cook et al., 2004, 2003). Corn earworm is especially challenging for organic sweet corn growers because few effective management strategies are permissible under the National Organic Program (NOP) (Cook et al., 2003, 2004; Moore and Tracy, 2020; Ni et al., 2011). Organic producers are in particular need of breeding for resistance to corn earworm as the advent of transgenic $B t$ cultivars has supplanted classical breeding for earworm resistance. However, novel forms of corn earworm resistance are of interest to conventional farmers as well because increasing reports of $B t$ resistance indicate a limited lifespan for one of their main management tools (Reisig and Reay-Jones, 2015; Tabashnik and Carriere, 2015; Tabashnik et al., 2009).

Husk traits (e.g., husk extension past the ear tip, husk tightness) have been proposed as physical mechanisms of earworm resistance (Barber, 1936, 1941, 1944; Collins and Kempton, 1917; Kyle, 1918; Phillips and King, 1923). Over the decades, many studies have evaluated husk extension and tightness as corn earworm resistance factors, but results have been mixed. Some studies have shown strong negative relationships between corn earworm damage and husk extension,

Received for publication 17 July 2020. Accepted for publication 28 Sept. 2020. Published online 17 November 2020.

This paper is based on research that is supported by the National Institute of Food and Agriculture, U.S. Department of Agriculture, under award 201451300-22223, the Clif Bar Family Foundation and Organic Valley Endowed Chair for Organic Plant Breeding, and the College of Agricultural and Life Sciences.

Current address for V.M.M.: Beltsville Agricultural Research Center, 10300 Baltimore Avenue, Building 001, Room 010, Beltsville, MD 20705

V.M.M. is the corresponding author. E-mail: vmmoore3@ncsu.edu.

This is an open access article distributed under the CC BY-NC-ND license (https://creativecommons.org/licenses/by-nc-nd/4.0/). husk tightness, or both (Collins and Kempton, 1917; Del Valle and Miller, 1963; Douglas, 1947; Kyle, 1918; Ni et al., 2007, 2008). However, a number of studies have shown an inconsistent or absent relationship between corn earworm damage and husk characteristics (Moore and Tracy, 2019; Ni et al., 2012; Painter and Brunson, 1940; Snyder, 1967; Yadav, 1980), or even a positive relationship between damage and husk characteristics (Widstrom et al., 1970).

Another promising proposed corn earworm resistance trait is the presence of the C-glycosyl flavone maysin, which is produced in the silks of some corn cultivars. Maysin content is highly heritable (Straub et al., 1973; Widstrom and Snook, 2001), and it has been shown in larval feeding studies to delay development and reduce reproduction even at lower doses (Bennett et al., 1967; Olmstead et al., 2016; Straub and Fairchild, 1970; Wiseman and Carpenter, 1995; Wiseman and Isenhour, 1990; Wiseman et al., 1983). However, evidence from the field is mixed; neither Rector et al. (2002) nor Ni et al. (2008) found a relationship between corn earworm damage and maysin content in the field.

Although neither husk traits nor maysin seem to consistently demonstrate resistance to the corn earworm, some studies have indicated that they may perform better in combination (Bennett et al., 1967; Rector et al., 2002). The number of studies deploying these traits in combination remain limited and have mostly been conducted in field corn backgrounds, and to our knowledge, no commercial corn hybrids have been released that integrate these two traits. In this experiment, a factorial mating design was used to test hybrid combinations of sweet corn inbreds with long husks and/or maysin to identify candidates for future cultivar development.

\section{Materials and Methods}

Mating Design. Twelve sweet corn inbred lines were included as parents in this study. Seven inbreds were used as pollen parents (males), and five were used as seed parents (females). The seven males included three standard three standard commercial sweet corn inbreds (Wh9261, We11401, 
and Wt1001) and four inbreds selected for maysin content (Maysin1, 2, 3, and 4). Maysin1 and Maysin2 were both developed from maysin-containing inbreds backcrossed to Wh9261, Maysin3 was developed from a maysin inbred backcrossed to Wt1401, and Maysin4 was developed from a maysin inbred backcrossed to Wt1001. Each line underwent five backcrosses and at least three generations of self-pollination, and may be considered near-isogenic. Maysin3's parent line was not included in the mating design due to different maturity timing compared with the other inbreds. The females included two standard commercial sweet corn inbreds (Ia453su and Ia5125su) and three inbreds with long, thick, tight husks (A684su, A685su, and A686su), which were derived from an 'Apache'/Ia453/B52 background and were originally selected for resistance to the european corn borer [Ostrinia nubilalis (Davis et al., 1993)]. In the summer of 2015, the five female parents were crossed to each of the seven male parents in a North Carolina Design II (Comstock and Robinson, 1952), for a total of 35 hybrids.

Field Evaluation. In Summers 2016 and 2017, hybrids were evaluated for ear length, husk length, maysin content, and corn earworm resistance. The 35 hybrids were planted in tworow plots ( $3.5 \mathrm{~m}$ long, 12 plants per row, and $0.76 \mathrm{~m}$ betweenrow spacing) in an incomplete block design, with each genotype replicated two to four times, depending on seed availability. In 2016, the experiment was planted in four environments: two at West Madison Agricultural Research Station in Madison, WI (WMARS), and two at Arlington Agricultural Research Station in Arlington, WI (AARS), with planting dates of 19 May and 2 June at WMARS and 20 May and 7 June at AARS). In 2017, two environments were planted at WMARS on 15 May and 1 June).

Corn earworm pressure is unpredictable in south-central Wisconsin, so to evaluate resistance to corn earworm, ears were artificially infested with corn earworm eggs. Corn earworm eggs were ordered from Benzon Research (Carlisle, PA) every 3 to $4 \mathrm{~d}$. Eggs were suspended in $0.2 \%$ agar solution, and the agar-egg solution was applied to fresh corn silks using a pressure applicator at an estimated rate of 15 to 30 eggs per ear (Mihm, 1982; Widstrom and Burton, 1970; Wiseman et al., 1974). Eggs were applied to the left row of each two-row plot when $75 \%$ of plants had fresh silks (nine plants per row, or fewer depending on germination and maturity). Plants were tagged and eggs were reapplied to the same plants $7 \mathrm{~d}$ later to ensure uniform infestation (Widstrom and Burton, 1970).

At the time of the first egg application, silks were also harvested from the first two replications at each environment for analysis of maysin content. Silks were sampled from six plants in the right row in each plot. Exposed silks were clipped and discarded, and 2 to $3 \mathrm{~cm}$ of the remaining silk (protected by the silk channel) was collected from the plants and bulked (Widstrom et al., 1982). Silks were placed in a 50-mL conical centrifuge tube, covered with 100\% methanol, and frozen for future extraction (Gueldner et al., 1992). Weight of both silks and methanol were recorded for future calculation of methanol content.

Evaluation of ear length, husk length, and corn earworm damage took place during milk stage; we harvested the first inoculated plots $21 \mathrm{~d}$ after the first inoculation, and we harvested subsequent plots according to the growing degree days of the first harvest to ensure all plots were harvested at a comparable stage. The tagged ears were harvested, and each ear was evaluated for ear length, husk length, number of corn earworms present, number of damaged kernels, and length of damaged area at the ear tip. Length of damaged area was assessed using the revised centimeter scale (RCS) described by Widstrom (1967), such that a rating of 0 corresponds to no damage, a rating of 1 corresponds to damage to silks only, a rating of 2 corresponds to feeding up to $1 \mathrm{~cm}$ below the ear tip, and the rating increases by one for each additional $1 \mathrm{~cm}$ of feeding.

Maysin SCREening. Maysin content of the harvested silks was determined by measuring ultraviolet absorption. Different authors have identified slightly different maysin absorbance peaks. Snook et al. (1989) and Gueldner et al. (1992) measured maysin at $340 \mathrm{~nm}$, Casati and Walbot (2005) identified a peak at $345 \mathrm{~nm}$, and Waiss et al. (1979) and Widstrom et al. (1991) measured maysin at $352 \mathrm{~nm}$. Notably, Waiss et al. (1979) found that maysin represented only about half of the relative absorption intensity in some lines of corn, with other flavonoids representing the remaining portion. Other, more accurate methods of measuring maysin content such as high-performance liquid chromatography (HPLC) and thin layer chromatography have since been developed, but these methods were impractical for this experiment due to the large number of samples. Widstrom et al. (1991) found that estimates of maysin content derived from spectrophotometric absorbance were similar to those derived from HPLC but had larger variance.

Ultraviolet absorption was measured using a ultraviolet-Vis spectrophotometer (Evolution; ThermoFisher Scientific, Waltham, MA). Twenty microliters of methanol was extracted from each silk sample and diluted with $2.98 \mathrm{~mL}$ of methanol. We measured absorbance at all three putative absorbance peaks $(340,345$, and $352 \mathrm{~nm})$. To calculate the approximate quantity of maysin, the readings were compared with a pure maysin standard (acquired from M.E. Snook) and diluted with methanol to a concentration of $10,000 \mathrm{nmol}$.

Data analysis. The four dependent variables were husk extension past the ear tip, maysin concentration, rate of infestation, and corn earworm damage at the ear tip. Each of the four variables was evaluated on a plot-mean basis using a linear mixed effect model and included male parent $(M)$, female parent $(F)$, environment $(E), M \times F$ interaction, $E \times M$ interaction, $E \times F$ interaction, and $M \times F \times E$ interaction as fixed effects, and block within $E[B(E)]$ as a random effect. Maysin concentration was modeled at all three wavelengths. In all cases, the distribution was nonnormal, and Tukey's ladder of powers was used to find the most appropriate transformation for the data (Mangiafico, 2018).

In addition to the explanatory variables above, the infestation rate and extent of damage models included a rain date (RD) dummy variable as a covariate. During the period when the plots were inoculated in 2016 and 2017, there were several major rain events, which could have altered the frequency of successful inoculation (e.g., by washing eggs off the silks). To account for any rain effects on the success of inoculation and thus on subsequent earworm damage, the RD dummy variable was set to 1 if rain occurred following corn earworm inoculation, and 0 if rain did not occur.

For the models in which the $M \times F \times E$ interaction was significant, the Spearman rank correlation was calculated to determine whether the interaction effect was caused by a change in magnitude or a change in rank. Absent rank changes or significant interactions, environments were pooled for calculation of 
general combining ability (GCA) and specific combining ability (SCA). GCA and SCA were estimated across the four dependent variables to identify high-performing parent lines and hybrid combinations. Data were analyzed using the opensource statistical software ( $\mathrm{R}$ version $3.6 .1 ; R$ Foundation for Statistical Computing, Vienna, Austria) and RStudio (version 1.1.383; RStudio, Boston, MA). Packages used in the analysis include ggplot2 (Wickham, 2009), lattice (Sarkar, 2008), lme4 (Bates et al., 2015), lmerTest (Kuznetsova et al., 2017), lsmeans (Lenth, 2016), multcomp (Hothorn et al., 2008), MuMIn (Barton, 2018), plyr (Wickham, 2011), and rcompanion (Mangiafico, 2018).

\section{Results}

Husk extension. Effects of $E, M, F$, all two-way interactions, the three-way interaction, and replication were significant (Table 1). We calculated the Spearman's rank correlation among ranks of each hybrid combination between environments and found that all environments were strongly correlated, indicating that although the $E x M x F$ interaction was significant, this effect was primarily due to changes in magnitude rather than rank. The environments were therefore pooled to analyze the GCA and SCA values for husk extension.

Some parents produced hybrids with remarkably consistent husk extension, regardless of the other parent to which they were crossed. For example, Maysin 1 and Maysin 2 (males) and Ia453 (female) produced hybrids with short husk extension even when crossed to otherwise long-husked parents (Fig. 1). This trend is also captured in the negative GCA values for these inbreds (Table 2). Other inbreds, including Ia5125, another short-husked parent, showed more variation depending on the cross. Likewise, among the long-husked parents, A684 and

Table 1. Analysis of variance for husk extension, maysin concentration, corn earworm infestation rate, and corn earworm damage in sweet corn hybrids. All traits were evaluated on a plot-mean basis using linear mixed effect models. $F$ statistic is reported for fixed effects, and $\chi^{2}$ is reported for random effects.

\begin{tabular}{|c|c|c|c|c|}
\hline \multirow[b]{2}{*}{ Source } & Husk extension $^{z}$ & Maysin concn ${ }^{y}$ & Infestation rate $^{\mathrm{x}}$ & Damage $^{\mathrm{w}}$ \\
\hline & \multicolumn{4}{|c|}{$F$ value } \\
\hline Environment (E) & $9.2 * * *$ & $8.0^{*}$ & $24.0 * * *$ & 0.4 \\
\hline Rain date & $\mathrm{NA}^{\mathrm{v}}$ & $\mathrm{NA}^{\mathrm{v}}$ & $35.0 * * *$ & 1.0 \\
\hline Male (M) & $298.0 * * *$ & $574.4 * * *$ & $21.6^{* * *}$ & $7.6^{* * *}$ \\
\hline Female (F) & $75.5 * * *$ & $469.0 * * *$ & 1.4 & $87.9 * * *$ \\
\hline $\mathrm{M} \times \mathrm{F}$ & $29.5 * * *$ & $6.3 * * *$ & $1.7 *$ & $2.1 * *$ \\
\hline $\mathrm{E} \times \mathrm{M}$ & $2.9 * * *$ & $3.9 * * *$ & $1.6^{*}$ & $2.1 * * *$ \\
\hline $\mathrm{E} \times \mathrm{F}$ & $2.1 * *$ & $2.0 * *$ & 1.2 & $2.0 * *$ \\
\hline $\mathrm{E} \times \mathrm{M} \times \mathrm{F}$ & $1.8^{* * *}$ & $1.5 * *$ & 1.1 & 1.0 \\
\hline Block $\times E$ & \multicolumn{4}{|c|}{$\chi^{2}$} \\
\hline
\end{tabular}

${ }^{\mathrm{z}}$ Husk extension was measured as the husk length (centimeters) past the ear tip.

${ }^{\mathrm{y}}$ Maysin concentration was measured as ultraviolet absorption at a wavelength of $340 \mathrm{~nm}$, and the concentration was raised to the 0.475 power according to results of Tukey's ladder of powers.

${ }^{\mathrm{x}}$ Infestation rate was calculated as the proportion of ears infested per inoculated ears.

${ }^{\mathrm{w}}$ Corn earworm damage was measured using the revised centimeter scale, such that a rating of 0 corresponds to no damage, a rating of 1 corresponds to damage to silks only, a rating of 2 corresponds to feeding up to $1 \mathrm{~cm}$ below the ear tip, and the rating increases by one for each additional $1 \mathrm{~cm}$ of feeding.

${ }^{\mathrm{v}}$ Rain date was included as a fixed effect in the corn earworm infestation rate and damage models only.

$*, * *, * * *$ Significant at $0.05,0.01$, or 0.001 , respectively.
A685 had similar husk extension values when crossed to some males (e.g., Maysin3, Maysin4, We11401) but diverged when (e.g., Wt1001). Interestingly, Maysin 1 sion than their parental line Wh9261, despite their close relatedness (Fig. 1). Across all hybrids, there was a grand mean extension of $2.95 \mathrm{~cm}$. Two of the long-husked female ) and three male parents (Maysin3, and $2.47 \mathrm{~cm}$ ), while the two short-husked females (Ia 453 and 125) and three of the male parents (Maysin1, Maysin2, and cm) (Table 2).

Eleven of the 35 hybrids had positive SCA values, indicating that they performed better in terms of husk extension than be predicted from the GCAs of their parents (Table 3). and Maysin 4), they produced hybrids with significant, positive CAs, and A684 also produced longer-husked hybrids when roduce especially long-husked cultivars.

Maysin CONCENTRATION. The mean maysin readings across plots for the three wavelengths was $0.39 \%$ (at $340 \mathrm{~nm}$ ), maysin concentration of $0.2 \%$ was sufficient to reduce larval growth by $50 \%$ when fed an exclusively silk diet. Waiss et al. in some lines, half of the absorbance signal tration of maysin was likely lower, and given that tissues other than silk (e.g., kernels) were available for larval consumption, the effect of maysin on larval growth and development may have been reduced. Nevertheless, the absorbance signal was high enough in some hybrids that an effect on corn earworm resistance is plausible.

We ran three separate linear mixed effects models to analyze absorbance data at each of the three tested wavelengths $(340,345$, and $352 \mathrm{~nm})$. In all three data sets, the quantile-quantile plot showed nonnormality in the data, and the data were transformed according to Tukey's ladder of powers to produce a more normal distribution. Results from the analysis of variance and GCA/SCA calculations were virtually identical across wavelengths, so only results from the $340-\mathrm{nm}$ wavelength are presented. Results in Fig. 2 display untransformed data to give a relative sense of the range of actual absorbance signals, whereas GCA and SCA values (Tables 2 and 3) were calculated from the transformed models in which maysin concentration was raised to the 


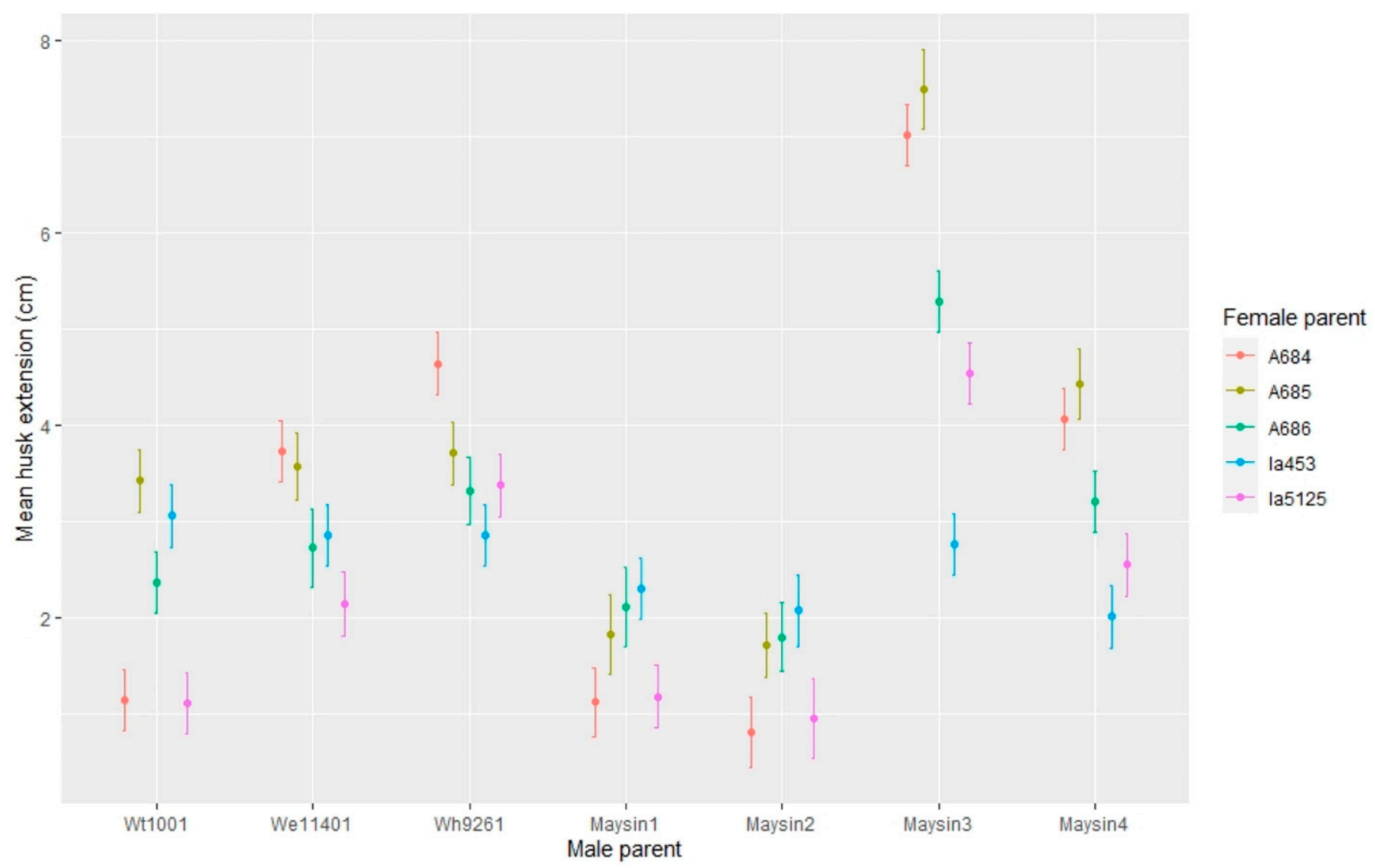

Fig. 1. Male $\times$ female interaction for husk extension among sweet corn hybrids. Husk extension was measured as the husk length past the ear tip. Male parents are displayed along the x-axis, and female parents are color-coded (see legend). Points indicate the mean husk extension for each hybrid, and lines correspond to the $95 \%$ confidence interval.

Table 2. General combining ability (GCA) for husk extension, maysin concentration, corn earworm infestation rate, and corn earworm damage in sweet corn inbreds.

\begin{tabular}{|c|c|c|c|c|c|}
\hline $\begin{array}{l}\text { Parent } \\
\text { identity }\end{array}$ & $\begin{array}{c}\text { Parent } \\
\text { type }\end{array}$ & $\begin{array}{c}\text { GCA: husk } \\
\text { extension }(\mathrm{cm})^{\mathrm{z}}\end{array}$ & $\begin{array}{l}\text { GCA: Maysin } \\
\text { concn }\left(\% \%^{0.475}\right)^{y}\end{array}$ & $\begin{array}{l}\text { GCA: infestation } \\
\text { rate }(0 \text { to } 1 \text { scale })^{\mathrm{x}}\end{array}$ & $\begin{array}{l}\text { GCA: earworm } \\
{\text { damage }(\mathrm{RCS})^{\mathrm{w}}}\end{array}$ \\
\hline Grand mean & & 2.95 & 0.58 & 0.65 & 5.0 \\
\hline A684 & Female & $0.27 *$ & $0.05 *$ & -0.03 & $-0.25^{*}$ \\
\hline A686 & Female & 0.02 & $0.13^{*}$ & 0.004 & $-0.48^{*}$ \\
\hline Ia453 & Female & $-0.39^{*}$ & $-0.29 *$ & 0.01 & -0.08 \\
\hline Ia5125 & Female & $-0.69 *$ & $0.05^{*}$ & 0.03 & $1.55^{*}$ \\
\hline Maysin 2 & Male & $-1.48 *$ & $0.31 *$ & -0.04 & 0.09 \\
\hline Maysin3 & Male & $2.47 *$ & 0.003 & $-0.09 *$ & $-0.51 *$ \\
\hline Maysin 4 & Male & $0.30 *$ & 0.01 & $0.08^{*}$ & 0.09 \\
\hline Wt1001 & Male & $-0.73 *$ & $-0.17 *$ & $-0.13 *$ & $-0.28^{*}$ \\
\hline We11401 & Male & 0.06 & $-0.31^{*}$ & $0.12 *$ & $0.36^{*}$ \\
\hline Wh9261 & Male & $0.63 *$ & $-0.08^{*}$ & $0.08 *$ & $0.28 *$ \\
\hline
\end{tabular}

${ }^{\mathrm{z}}$ Husk extension was measured as the husk length $(\mathrm{cm})$ past the ear tip.

${ }^{\mathrm{y}}$ Maysin concentration was measured as ultraviolet absorption at a wavelength of $340 \mathrm{~nm}$, and the concentration was raised to the 0.475 power according to results of Tukey's ladder of powers.

${ }^{\mathrm{x}}$ Infestation rate was calculated as the proportion of ears infested per inoculated ears.

${ }^{\mathrm{w}}$ Corn earworm damage was measured using the revised centimeter scale (RCS), such that a rating of 0 corresponds to no damage, a rating of 1 corresponds to damage to silks only, a rating of 2 corresponds to feeding up to $1 \mathrm{~cm}$ below the ear tip, and the rating increases by one for each additional $1 \mathrm{~cm}$ of feeding.

*GCA significantly different from the grand mean at the 0.05 level. 
Table 3. Specific combining ability (SCA) for husk extension, maysin concentration, corn earworm infestation rate, and corn earworm damage in pairs of sweet corn inbreds.

\begin{tabular}{|c|c|c|c|c|c|}
\hline Female & Male & $\begin{array}{c}\text { SCA: husk } \\
\text { extension }(\mathrm{cm})^{\mathrm{z}} \\
\end{array}$ & $\begin{array}{c}\text { SCA: haysin } \\
\text { concn }\left(\% \%^{0.475}\right)^{\mathrm{y}}\end{array}$ & $\begin{array}{l}\text { SCA: infestation } \\
\text { rate }(0 \text { to } 1 \text { scale })^{\mathrm{x}}\end{array}$ & $\begin{array}{l}\text { SCA: earworm } \\
\text { damage }(\mathrm{RCS})^{\mathrm{w}} \\
\end{array}$ \\
\hline A684 & Wt1001 & $-1.34^{*}$ & -0.03 & -0.01 & 0.26 \\
\hline A684 & We11401 & $0.46^{*}$ & 0.04 & 0.004 & -0.37 \\
\hline A684 & Maysin 1 & $-0.85^{*}$ & $-0.06^{*}$ & 0.02 & $0.67 *$ \\
\hline A684 & Maysin 2 & $-0.93 *$ & $-0.04 *$ & 0.06 & 0.25 \\
\hline A684 & Maysin3 & $1.33^{*}$ & 0.03 & 0.06 & -0.20 \\
\hline A685 & Wt1001 & $0.41 *$ & $-0.07 *$ & -0.02 & -0.31 \\
\hline A685 & We11401 & -0.22 & 0.0004 & -0.02 & -0.16 \\
\hline A685 & Wh9261 & $-0.65 *$ & 0.02 & -0.05 & 0.50 \\
\hline A685 & Maysin 1 & $-0.67 *$ & 0.01 & 0.09 & -0.11 \\
\hline A685 & Maysin 2 & $-0.54 *$ & 0.03 & -0.06 & 0.12 \\
\hline A685 & Maysin3 & $1.28^{*}$ & 0.04 & -0.001 & 0.04 \\
\hline A686 & Maysin 1 & 0.38 & -0.01 & -0.02 & -0.51 \\
\hline A686 & Maysin 2 & 0.31 & 0.03 & 0.04 & -0.05 \\
\hline A686 & Maysin 3 & -0.16 & 0.02 & -0.09 & 0.15 \\
\hline A686 & Maysin4 & -0.06 & 0.02 & -0.01 & -0.17 \\
\hline Ia453 & Wt1001 & $1.23^{*}$ & $0.05 *$ & -0.01 & -0.40 \\
\hline Ia453 & We11401 & 0.25 & $0.09^{*}$ & 0.02 & 0.31 \\
\hline Ia453 & Wh9261 & $-0.34^{*}$ & $-0.08^{*}$ & 0.07 & 0.07 \\
\hline Ia453 & Maysin1 & $0.98^{*}$ & $0.07^{*}$ & -0.05 & 0.39 \\
\hline Ia453 & Maysin 2 & $1.00 *$ & -0.01 & 0.02 & -0.22 \\
\hline Ia453 & Maysin3 & $-2.27 *$ & $-0.07 *$ & 0.003 & -0.14 \\
\hline Ia453 & Maysin4 & $-0.85^{*}$ & $-0.04 *$ & -0.06 & -0.01 \\
\hline
\end{tabular}

${ }^{\mathrm{z}}$ Husk extension was measured as the husk length (centimeters) past the ear tip.

${ }^{\mathrm{y}}$ Maysin concentration was measured as ultraviolet absorption at a wavelength of $340 \mathrm{~nm}$, and the concentration was raised to the 0.475 power according to results of Tukey's ladder of powers.

${ }^{\mathrm{x}}$ Infestation rate was calculated as the proportion of ears infested per inoculated ears.

${ }^{\mathrm{w}}$ Corn earworm damage was measured using the revised centimeter scale (RCS), such that a rating of 0 corresponds to no damage, a rating of 1 corresponds to damage to silks only, a rating of 2 corresponds to feeding up to $1 \mathrm{~cm}$ below the ear tip, and the rating increases by one for each additional $1 \mathrm{~cm}$ of feeding.

*SCA significantly different from the mean of parental combination at the 0.05 level.

0.475 power according to results of the Tukey's ladder of powers. Therefore, the GCA and SCA values should be interpreted in terms of relative rather than absolute values.

Effects of $E, M, F$, all two-way interactions, the three-way interaction, and the replication effect were significant at the 0.05 level (Table 1). We conducted a Spearman's rank correlation among ranks of each hybrid combination between environments and found that all environments were strongly correlated, indicating that although the $E \times M \times F$ interaction was significant, this effect was primarily due to changes in magnitude rather than rank. The environments were therefore pooled to analyze the GCA and SCA values for husk extension.
Maysin1 and Maysin2 produce hybrids with the highest maysin readings, indicating successful backcross selection for maysin content compared with their non-maysin parent lines, whereas Maysin3, Maysin4, and Wh9261 produced hybrids with intermediate values (Fig. 1). In general, male parents produced relatively consistent maysin readings regardless of the female parent to which they were crossed; Maysin1 and Maysin 2 produced hybrids with consistently higher readings, whereas Wt1001 and We11401 produced hybrids with consistently low readings (Fig. 2). However, the female parent Ia453 was a major exception; its hybrids registered values approaching zero except when crossed to Maysin1 and Maysin2, and 


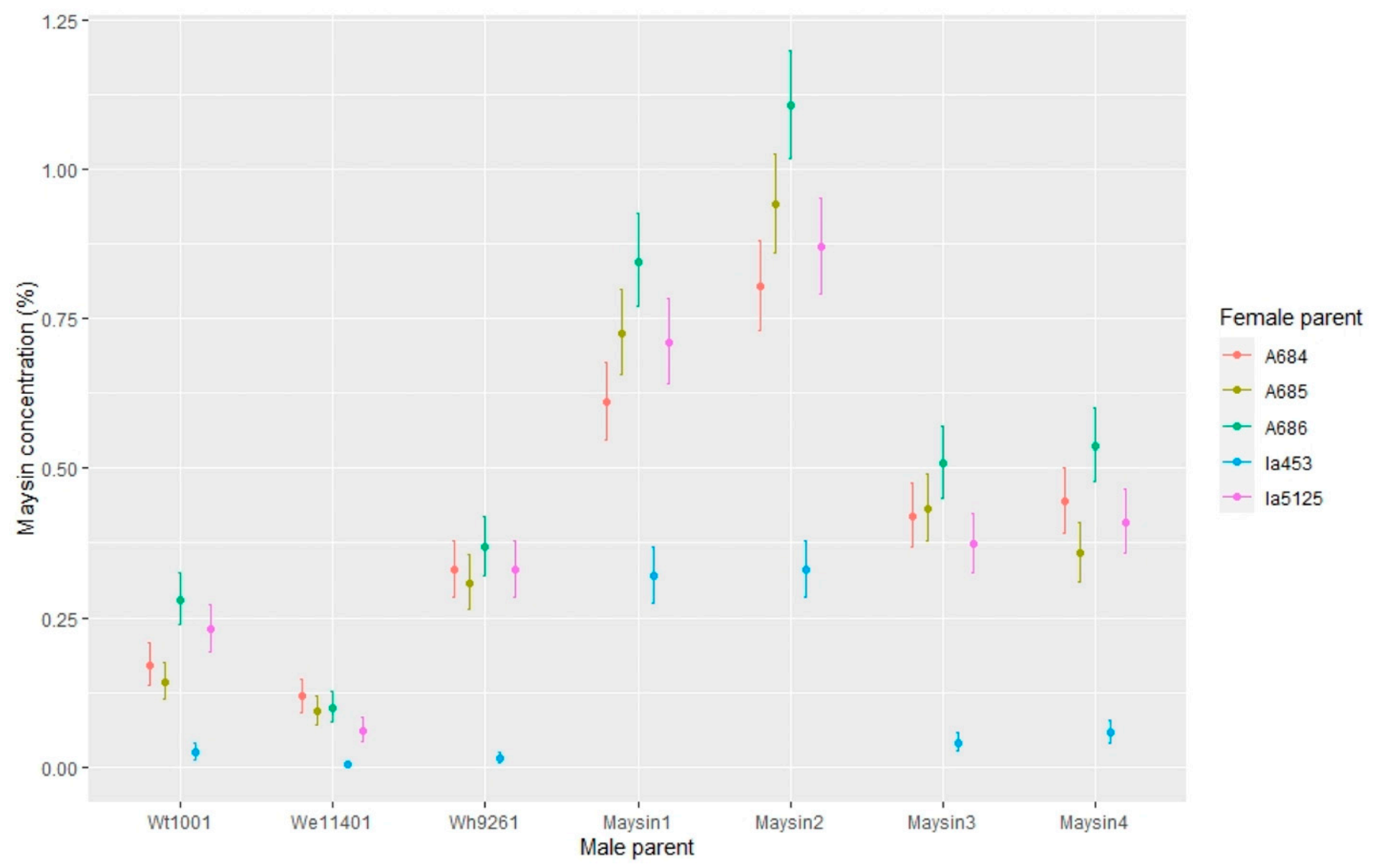

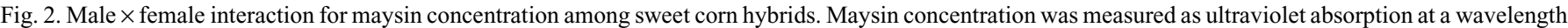
of $340 \mathrm{~nm}$, and the concentration was raised to the 0.475 power according to results of Tukey's ladder of powers. Male parents are displayed along the $\mathrm{x}$-axis, and female parents are color-coded (see legend). Points indicate the mean maysin concentration for each hybrid, and lines correspond to the $95 \%$ confidence interval.

even these hybrids had much lower readings than other hybrids of Maysin1 and Maysin2 (Fig. 2).

Across all hybrids, there was a grand mean transformed maysin content of 0.58. Among the female parents, A684, A685, A686, and Ia5125 had positive GCA values (between 0.05 and 0.13$)$. Ia453 had a negative GCA value $(-0.29)$. Among the male parents, Maysin1 and Maysin2 had positive GCAs (0.22 and 0.31, respectively), and the GCAs for Maysin3 and Maysin4 were not significant. The three commercial inbreds had negative GCAs (between -0.31 and -0.08 ) (Table 2 ). Eleven of the 35 hybrids had significant SCA values. However, none of the crosses between high-GCA parents had significant, positive SCA values. Crosses between A684 and Maysin1 and Maysin2 (which all had significant, positive GCA values) had significant, negative SCA values (Table 3 ).

INFESTATION RATE. Effects of $E, R D, M, M \times F$ interaction; $E \times M$ interaction; and $B(E)$ were significant for infestation rate at the 0.05 level or less. $F, E \times F$ interaction, and the $E \times M \times F$ interaction were not significant (Table 1).

Most male parents produced hybrids with consistent infestation rates regardless of the female they were crossed to, but Wh9261 showed more differentiation among females, with the long-husk parents having lower infestation rates than the commercial inbreds. The female parents had similar mean infestation rates and wide variation depending on the male parent to which they were crossed. The hybrids of Maysin1 and Maysin2 showed lower infestation rates than those of Wh9261 when crossed to some females, whereas hybrids of Maysin 4 showed higher infestation rates than those of Wt1001 when crossed to some females. This indicates an inconsistent relationship between maysin content infestation rate even in lines with similar genetic backgrounds (Fig. 3).

Across all hybrids, there was a grand mean infestation rate of 0.65 . None of the female parents had significant GCAs for infestation rate. Among the males, Maysin3 and Wt1001 had negative GCAs ( -0.09 and -0.13 , respectively), indicating their hybrids had lower infestation rates than the grand mean. Maysin4, We11401, and Wh9261 had positive GCAs (between 0.08 and 0.12 ), indicating their hybrids had higher infestation rates than the grand mean (Table 2). Only two SCA values were significant, and none of these values corresponded to pairs of parents with low GCA values (Table 3), so no pairs of parents with high breeding potential were identified.

Corn Earworm Damage. Effects of $M, F$, all two-way interactions, and $B(E)$ were significant at the 0.01 level or less. $E, R D$, and the three-way interaction were not significant (Table $1)$.

Among female parents, Ia5125 produced hybrids with high damage ratings regardless of the male parent to which it was crossed, with means between 6 and 7 on the RCS scale. Otherwise, female parents produced hybrids with somewhat less damage (means between 3.5 and 5.5 on the RCS scale) and with some variation depending on the male. Some males (Wt1001, Wh9261, Maysin2, Maysin3) produced hybrids with 


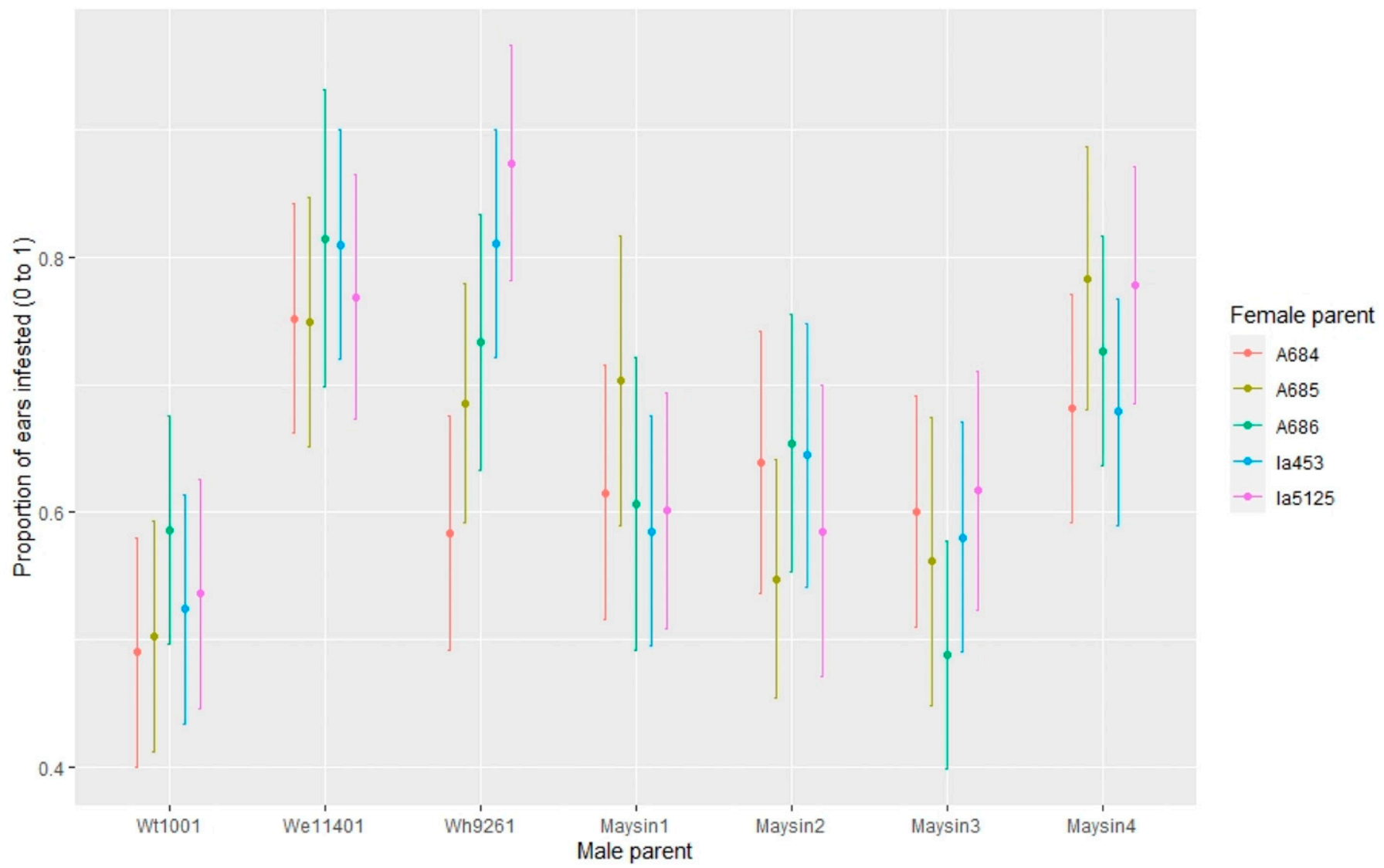

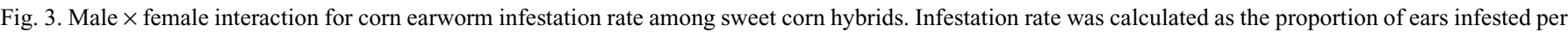
inoculated ears. Male parents are displayed along the $\mathrm{x}$-axis, and female parents are color-coded (see legend). Points indicate the mean infestation rate for each hybrid, and lines correspond to the $95 \%$ confidence interval.

consistent damage regardless of female parent (except when crossed to Ia5125), but others (We11401, Maysin1, Maysin4) showed more separation depending on female parent, with Ia453 producing hybrids with somewhat higher damage (Fig. 4).

Across all hybrids, there was a grand mean damage rating of 5.0. Among females, all three long-husked inbreds had negative GCAs (between -0.71 and -0.25 ), indicating that they had hybrids with significantly less damage than the grand mean. Ia5125 had a positive GCA (1.55), and Ia453 was not significantly different from the mean. Among males, Maysin3 and Wt1001 had negative GCAs ( -0.51 and -0.28 respectively); We11401 and Wh9261 had positive GCAs (0.36 and 0.28 respectively); and the GCAs of Maysin1, Maysin2, and Maysin 4 were not significantly different from the grand mean (Table 2). Only two SCA values were significant, and none of these values corresponded to pairs of parents with low GCA values (Table 3), which means no pairs with particularly low damage ratings were identified.

Correlation among traits. Pearson correlation coefficients between traits were calculated using the estimated values of each hybrid. Husk extension and corn earworm damage were negatively correlated $(-0.40)$, and infestation rate and corn earworm damage were positively correlated $(0.35)$. No other significant relationships were detected.

ENVIRONMENTAL INTERACTIONS. There were significant interactions between environment and the male and/or female parent for all four traits of interest (Table 1). Most hybrids did not show differences in husk extension between environments, but hybrids with Ia453 had longer husks in the 2016 AARS late planting than in all other environments, and the 2017 WMARS late planting had shorter husks than the early planting at the same location. In addition, hybrids with We11401, Wh9261, or Maysin4 had shorter husks in the 2017 WMARS late planting than in some other environments. Some genotypes also produced slightly higher maysin readings in the 2016 AARS late planting compared with other environments. In terms of infestation rate, in general the 2016 AARS late planting and both 2017 environments showed lower rates, but the differences in infestation rate were smaller in the hybrids with We11401 or Wh9261 (i.e., their hybrids had consistently high infestation rates regardless of environment). Finally, the variability of damage ratings within parents varies across environments, leading to significant differences between parents in some environments but not others. For example, for each male parent there was a much narrower spread of damage values at the 2017 WMARS early planting and a much wider spread of damage values at the 2016 AARS late planting.

\section{Discussion}

Evidence in the literature on the efficacy of husk extension (Collins and Kempton, 1917; Del Valle and Miller, 1963; Douglas, 1947; Kyle, 1918; Moore and Tracy, 2019; Ni et al., 


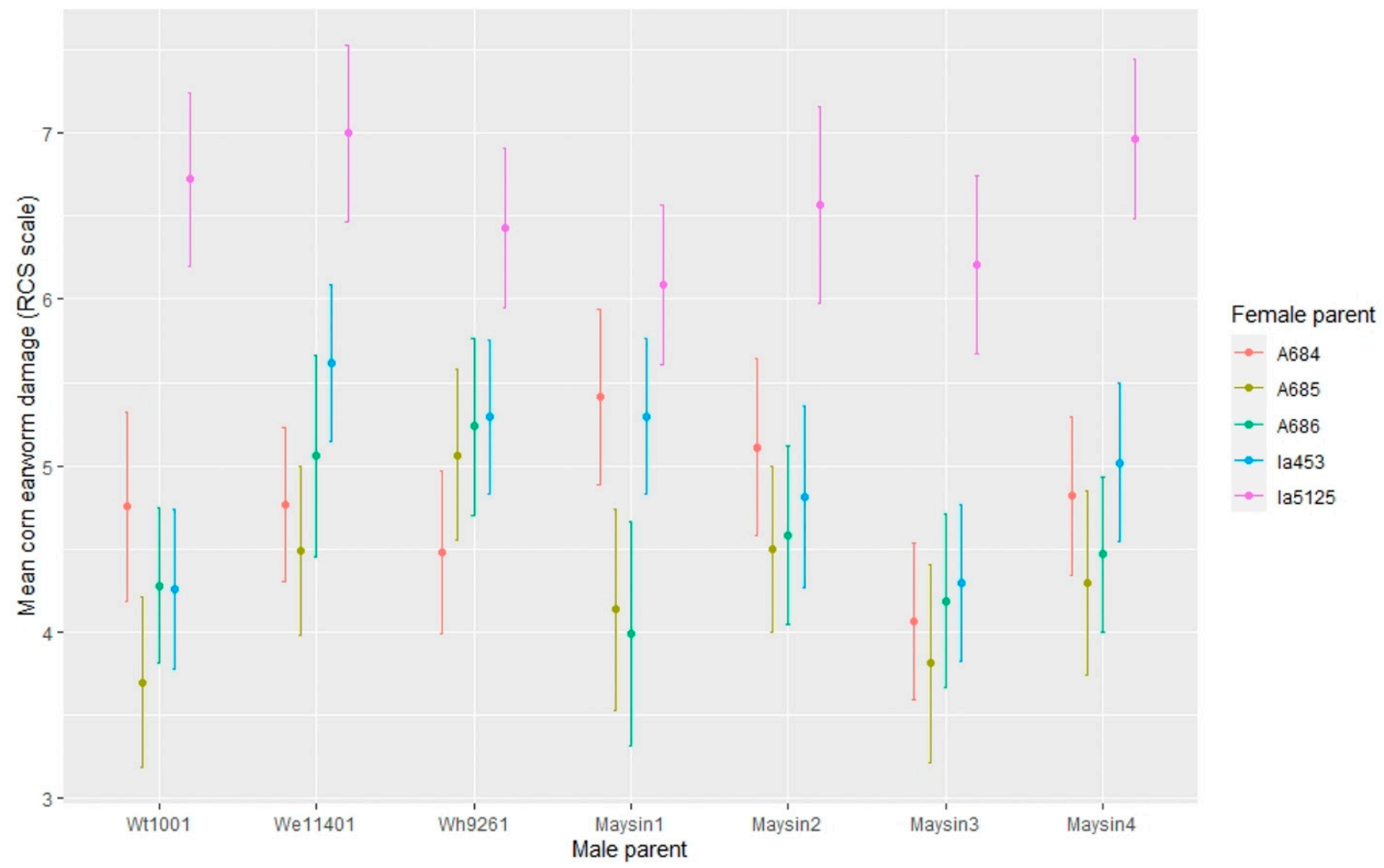

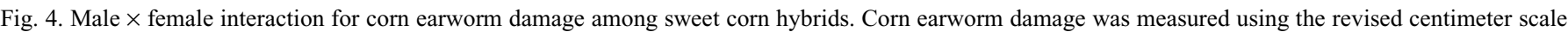
(RCS), such that a rating of 0 corresponds to no damage, a rating of 1 corresponds to damage to silks only, a rating of 2 corresponds to feeding up to $1 \mathrm{~cm}$ below the ear tip, and the rating increases by one for each additional $1 \mathrm{~cm}$ of feeding. Male parents are displayed along the x-axis, and female parents are color-coded (see legend). Points indicate the mean corn earworm damage for each hybrid, and lines correspond to the $95 \%$ confidence interval.

2007, 2008, 2012; Painter and Brunson, 1940; Snyder, 1967; Widstrom et al., 1970; Yadav, 1980) and mayin content (Bennett et al., 1967; Ni et al., 2008; Olmstead et al., 2016; Rector et al., 2002; Straub and Fairchild, 1970; Wiseman and Carpenter, 1995; Wiseman and Isenhour, 1990; Wiseman et al., 1983 ) in improving resistance to corn earworm is mixed. In this study, we made several observations that indicate husk extension as a source of corn earworm resistance in sweet corn. Female parent, which represents designated short- vs. longhusked parents, was a significant factor in the corn earworm damage model (Table 1), and the progeny of the designated longhusked inbreds (A684, A685, and A686) had consistently low corn earworm damage (Fig. 4). In addition, all three long-husked inbreds had negative GCAs for corn earworm damage, indicating less damage than the grand mean (Table 2), and we found a negative correlation between husk extension and corn earworm damage among hybrids. These data point to the potential for longer husks to reduce the distance corn earworm larvae travel past the ear tip and thus reduce the extent of damage to the ear. However, we did not find evidence that longer husk extension reduces the overall rate of corn earworm infestation. Female parent was not significant in the infestation rate model (Table 1). We did not observe differences in infestation rate between the progeny of long- vs. short-husked inbreds (Fig. 3), significant GCA values for any of the female parents (Table 2), or correlation between husk extension and infestation rate.
Male parent, which represents designated maysin vs. nonmaysin parents, was a significant factor in both the corn earworm infestation rate and damage models (Table 1). However, the progeny of the designated maysin inbreds did not show consistently lower infestation rates or damage (Figs. 3 and 4), nor was there a correlation between maysin concentration and either infestation rate or damage. Maysin1 and Maysin2 produced progeny with the highest maysin concentrations, but Maysin3, which produced progeny with lower maysin concentrations but longer husk extension (Figs. 1 and 2), had negative GCAs for infestation rate and damage (Table 2). Although neither husk extension nor maysin concentration appear correlated with infestation rate, this study only examined infestation rate in the context of artificial inoculation. We measured the likelihood of earworm larvae reaching the ear once oviposition has occurred, but do not address any potential impact on the likelihood of oviposition to occur.

Only Maysin3 and Wt1001 had negative GCAs for infestation rate. These two inbreds plus the designated long-husked inbreds (A684, A685, and A686) had negative GCAs for earworm damage (Table 2). With the exception of Wt1001, these inbreds had long husks and/or higher absorbance readings. However, other inbreds with these traits did not perform as well in terms of earworm damage, and Wt1001 had both short husks and low maysin readings, so it appears that the relationship between husk extension and maysin content are not 
straightforward. It is possible that maysin absorbance readings may have been confounded with compounds that produce similar peaks, or other traits not measured in this study may also mediate corn earworm resistance.

As a result of this study, we have identified sweet corn inbreds with the potential to confer resistance to the corn earworm. As these inbreds are integrated into breeding programs, it will be important to explore the mechanisms of resistance, especially given that the interactions between resistance mechanisms remain difficult to predict.

In addition, it will be important to determine whether the differences in corn earworm damage are statistically but also economically significant. Some markets require "clean" ears (absent any earworm damage), and reducing the damage from the ear tip will be insufficient. There were few significant differences among inbreds in terms of infestation rate, but the results may be a function of the inoculation method and do not necessarily reflect the likely differences in natural infestations. To draw conclusions about such effects, experiments using natural corn earworm infestations, either in regions with more consistent corn earworm infestations or with many on-farm replicates across the region of interest.

\section{Literature Cited}

Barber, G.W. 1936. The cannibalistic habits of the corn ear worm. U.S. Dept. Agr. Tech. Bul. 499.

Barber, G.W. 1941. Observations on the egg and newly hatched larva of the corn ear worm on corn silk. J. Econ. Entomol. 34(3):451-456, doi: $10.1093 /$ jee/34.3.451.

Barber, G.W. 1944. Husk development of sweet corn as affected by moisture supply, an important factor in corn earworm control. J. Agr. Res. 68(2):73-77.

Barton, K. 2018. MuMIn: Multi-model inference. R package version 1.40.4. 1 Oct. 2020. <https://CRAN.R-project.org/package=MuMIn>. Bates, D., M. Mächler, B. Bolker, and S. Walker. 2015. Fitting linear mixed-effects models using lme4. J. Stat. Softw. 67(1):1-48, doi: 10.18637/jss.v067.i01.

Bennett, S.E., L.M. Josephson, and E.E. Burgess. 1967. Field and laboratory studies on resistance of corn to the corn earworm. J. Econ. Entomol. 60(1):171-173, doi: 10.1093/jee/60.1.171.

Casati, P. and V. Walbot. 2005. Differential accumulation of maysin and rhamnosylisoorientin in leaves of high-altitude landraces of maize after UV-B exposure. Plant Cell Environ. 28:788-799, doi: 10.1111/j.1365-3040.2005.01329.x.

Collins, G.N. and J.H. Kempton. 1917. Breeding sweet corn resistant to the corn earworm. J. Agric. Res. 11(2):549-572.

Comstock, R.E. and H.F. Robinson. 1952. Estimation of average dominance of genes, p. 494-516. In: J. Gowen (ed.). Heterosis. Iowa State College Press, Ames, IA.

Cook, R., A. Carter, P. Westgate, and R. Hazzard. 2003. Direct silk applications of corn oil and Bacillus thuringiensis as a barrier to corn earworm larvae in sweet corn. HortTechnology 13(3):509-514, doi: 10.21273/HORTTECH.13.3.0509.

Cook, R., A. Carter, P. Westgate, and R. Hazzard. 2004. Optimum timing of an application of corn oil and Bacillus thuringiensis to control lepidopteran pests in sweet corn. HortTechnology 14(3):307314, doi: 10.21273/HORTTECH.14.3.0307.

Davis, D.W., D.A. Andow, and W.D. Hutchison. 1993. Registration of three european corn borer resistant sweet corn germplasm lines: A684su, A685su, and A686su. Crop Sci. 33(6):1422-1423, doi: 10.2135/cropsci1993.0011183X003300060086x.

Del Valle, C.G. and J.C. Miller. 1963. Influence of husk length and tightness against corn earworm damage in sweet corn hybrids. Proc. Amer. Soc. Hort. Sci. 83:531-535.
Douglas, W.A. 1947. The effect of husk extension and tightness on earworm damage on corn. J. Econ. Entomol. 40(5):661-664, doi: 10.1093/jee/40.5.661.

Gueldner, R.C., M.E. Snook, N.W. Widstrom, and B.R. Wiseman. 1992. TLC screen for maysin, chlorogenic acid, and other possible resistance factors to the fall armyworm and the corn earworm in Zea mays. J. Agr. Food Chem. 40(7):1211-1213, doi: 10.1021/ jf00019a027.

Hardwick, D.F. 1965. The corn earworm complex. Mem. Entomol. Soc. Can. 97(S40):5-247, doi: 10.4039/entm9740fv.

Hothorn, T., F. Bretz, and P. Westfall. 2008. Simultaneous inference in general parametric models. Biometrical J. 50(3):346-363, doi: 10.1002/bimj.200810425.

Huang, F. 2015. Resistance management for Bt maize and aboveground lepidopteran targets in the USA: From single-gene to pyramided traits, p. 173-185. In: M. Soberón (ed.). Bt Resistance: Characterization and strategies for GM crops producing Bacillus thuringiensis toxins, CABI Biotechnol. Ser. 4. CAB Intl., Boston, MA. Kennedy, G.G. and N.P. Storer. 2000. Life systems of polyphagous arthropod pests in temporally unstable cropping systems. Annu. Rev. Entomol. 45(1):467-493, doi: 10.1146/annurev.ento.45.1.467.

Kuznetsova, A., P.B. Brockhoff, and R.H.B. Christensen. 2017. lmerTest package: Tests in linear mixed effects models. J. Stat. Softw. 82(13):1-26, doi: 10.18637/jss.v082.i13.

Kyle, C.H. 1918. Shuck protection for ear corn. U.S. Dept. Agr. Tech. Bul. 708.

Lenth, R.V. 2016. Least-squares means: The R package lsmeans. J. Stat. Softw. 69(1):1-33, doi: 10.18637/jss.v069.i01.

Mangiafico, S. 2018. rcompanion: Functions to support extension education program evaluation. $\mathrm{R}$ package version 1.13.2. 1 Oct. 2020. $<$ https://CRAN.R-project.org/package $=$ rcompanion $>$.

Mihm, J.A. 1982. Techniques for efficient mass rearing and infestation in screening for host plant resistance to corn earworm, Heliothis zea. Centro Internacional de Mejoramiento de Maíz y Trigo (CIMMYT), El Batan, Mexico.

Moore, V.M. and W.F. Tracy. 2019. Recurrent full-sib family selection for husk extension in sweet corn. J. Amer. Soc. Hort. Sci. 144(1):6369, doi: 10.21273/JASHS04559-18.

Moore, V.M. and W.F. Tracy. 2020. Survey of organic sweet corn growers identifies corn earworm prevalence, management and opportunities for plant breeding. Renew. Agr. Food Syst. 1-4, doi: $10.1017 /$ S1742170520000204.

Neunzig, H.H. 1963. Wild host plants of the corn earworm and the tobacco budworm in eastern North Carolina. J. Econ. Entomol. 56(2):135-139, doi: 10.1093/jee/56.2.135.

Ni, X., W. Xu, M.D. Krakowsky, G.D. Buntin, S.L. Brown, R.D. Lee, and A.E. Coy. 2007. Field screening of experimental corn hybrids and inbred lines for multiple ear-feeding insect resistance. J. Econ. Entomol. 100(5):1704-1713, doi: 10.1603/0022-0493(2007)100 [1704:fsoech]2.0.co;2.

Ni, X., M.D. Krakowsky, G.D. Buntin, B.G. Rector, B. Guo, and M.E. Snook. 2008. Identification of multiple ear-colonizing insect and disease resistance in CIMMYT maize inbred lines with varying levels of silk maysin. J. Econ. Entomol. 101(4):1455-1465, doi: 10.1603/0022-0493(2008)101[1455:iomeia]2.0.co;2.

Ni, X., A.N. Sparks, D.G. Riley, and X. Li. 2011. Impact of applying edible oils to silk channels on ear pests of sweet corn. J. Econ. Entomol. 104(3):956-964, doi: 10.1603/EC10356.

Ni, X., W. Xu, M.H. Blanco, and J.P. Wilson. 2012. Evaluation of corn germplasm lines for multiple ear-colonizing insect and disease resistance. J. Econ. Entomol. 105(4):1457-1464, doi: 10.1603/EC12115.

Olmstead, D.L., B.A. Nault, and A.M. Shelton. 2016. Biology, ecology, and evolving management of Helicoverpa zea (Lepidoptera: Noctuidae) in sweet corn in the United States. J. Econ. Entomol. 109(4):1667-1676, doi: 10.1093/jee/tow125.

Painter, R.H. and A.M. Brunson. 1940. Differential injury within varieties, inbred lines, and hybrids of field corn caused by the corn earworm, Heliothis armigera (Hbn.). J. Agr. Res. 61(2):81-100. 
Phillips, W.J. and K.M. King. 1923. The corn earworm: Its ravages on field corn and suggestions for control. U.S. Dept. Agr. Farmers' Bul. 1310. 9 Sept. 2020. <https://digital.library.unt.edu/ark:/67531/ metadc6307/m1/17/>.

Pimentel, D., J. Friedman, and D. Kahn. 1997. Reducing insecticide, fungicide and herbicide use on vegetables and reducing herbicide use on fruit crops, p. 379-397. In: D. Pimentel (ed.). Techniques for reducing pesticide use: Economic and environmental benefits. Wiley, New York, NY.

Rector, B.G., M.E. Snook, and N.W. Widstrom. 2002. Effect of husk characters on resistance to corn earworm (Lepidoptera: Noctuidae) in high-maysin maize populations. J. Econ. Entomol. 95(6):1303-1307, doi: 10.1603/0022-0493-95.6.1303.

Reisig, D.D. and F.P.F. Reay-Jones. 2015. Inhibition of Helicoverpa zea (Lepidoptera: Noctuidae) growth by transgenic corn expressing $B t$ toxins and development of resistance to Cry1 Ab. Environ. Entomol. 44(4):1275-1285, doi: 10.1093/ee/nvv076.

Sarkar, D. 2008. Lattice: Multivariate data visualization with R. Springer-Verlag, New York.

Snook, M.E., N.W. Widstrom, and R.C. Gueldner. 1989. Reversedphase high-performance liquid chromatographic procedure for the determination of maysin in corn silks. J. Chromatography 477(2):439-447, doi: 10.1016/S0021-9673(01)89654-0.

Snyder, R.J. 1967. The relationship of silk balling, husk length, husk tightness and blank tip to earworm and sap beetle resistance in maize. Proc. Amer. Soc. Hort. Sci. 91:454-461.

Straub, R.W. and M.L. Fairchild. 1970. Laboratory studies of resistance in corn to the corn earworm. J. Econ. Entomol. 63(6):19011903, doi: 10.1093/jee/63.6.1901.

Straub, R.W., M.L. Fairchild, M.S. Zuber, and A.J. Keaster. 1973. Transmission of corn earworm resistance from Zapalote Chico to topcross progenies. J. Econ. Entomol. 66(2):534-536, doi: 10.1093/ jee/66.2.534.

Sudbrink, D.L. and J.F. Grant. 1995. Wild host plants of Helicoverpa zea and Heliothis virescens (Lepidoptera: Noctuidae) in eastern Tennessee. Environ. Entomol. 24(5):1080-1085, doi: 10.1093/ee/ 24.5.1080.

Tabashnik, B.E. and Y. Carriere. 2015. Successes and failures of transgenic $B t$ crops: Global patterns of field-evolved resistance, p. 114. In: M. Soberón (ed.). Bt resistance: Characterization and strategies for GM crops producing Bacillus thuringiensis toxins. CABI Biotechnol. Ser. 4. CAB Intl., Boston, MA.

Tabashnik, B.E., J.B.J. Van Rensburg, and Y. Carriere. 2009. Fieldevolved resistance to $B t$ crops: Definition, theory, and data. J. Econ. Entomol. 102(6):2011-2025, doi: 10.1603/029.102.0601.

Waiss, A.C., B.G. Chan, C.A. Elliger, B.R. Wiseman, W.W. McMillian, N.W. Widstrom, M.S. Zuber, and A.J. Keaster. 1979. Maysin, a flavone glycoside from corn silks with antibiotic activity toward corn earworm. J. Econ. Entomol. 72(2):256-258, doi: 10.1093/jee/ 72.2.256.
Wickham, H. 2009. ggplot2: Elegant graphics for data analysis. Springer-Verlag, New York, NY.

Wickham, H. 2011. The split-apply-combine strategy for data analysis. J. Stat. Softw. 40(1):1-29, doi: 10.18637/jss.v040.i01.

Widstrom, N.W. 1967. An evaluation of methods for measuring corn earworm injury. J. Econ. Entomol. 60(3):791-794, doi: 10.1093/jee/ 60.3.791.

Widstrom, N.W. and R.L. Burton. 1970. Artificial infestation of corn with suspensions of corn earworm eggs. J. Econ. Entomol. 63(2):443-446, doi: 10.1093/jee/63.2.443.

Widstrom, N.W. and M.E. Snook. 2001. Recurrent selection for maysin, a compound in maize silks, antibiotic to earworm. Plant Breed. 120:357-359, doi:10.1046/j.1439-0523.2001.00610.x.

Widstrom, N.W., W.W. McMillian, and B.R. Wiseman. 1970. Resistance in corn to the corn earworm and the fall armyworm. IV. Earworm injury to corn inbreds related to climatic conditions and plant characteristics. J. Econ. Entomol. 63(3):803-808, doi: 10.1093/ jee/63.3.803.

Widstrom, N.W., A.C. Waiss, W.W. McMillian, B.R. Wiseman, C.A. Elliger, M.S. Zuber, R.W. Straub, J.L. Brewbaker, L.L. Darrah, A.R. Henson, J.M. Arnold, and J.L. Overman. 1982. Maysin content of silks of nine maize genotypes grown in diverse environments. Crop Sci. 22(5):953-955, doi: 10.2135/cropsci1982.0011183X002200050013x.

Widstrom, N.W., M.E. Snook, W.W. McMillian, A.C. Waiss, and C.A. Elliger. 1991. Maize-silk maysin data: Comparison of interpretations of quantifications by spectrophotometry and HPLC. J. Agr. Food Chem. 39(1):182-184, doi: 10.1021/jf00001a036.

Wiseman, B.R. and J.E. Carpenter. 1995. Growth inhibition of corn ear worm (Lepidoptera: Noctuidae) larvae reared on resistant corn silk diets. J. Econ. Entomol. 88(4):1037-1043, doi: 10.1093/jee/ 88.4.1037.

Wiseman, B.R. and D.J. Isenhour. 1990. Effects of resistant maize silks on corn earworm (Lepidoptera: Noctuidae) biology: A laboratory study. J. Econ. Entomol. 83(2):614-617, doi: 10.1093/jee/83.2.614. Wiseman, B.R., N.W. Widstrom, and W.W. McMillian. 1974. Methods of application and numbers of eggs of the corn earworm required to infest ears of corn artificially. J. Econ. Entomol. 67(1):74-76, doi: 10.1093/jee/67.1.74.

Wiseman, B.R., N.W. Widstrom, and W.W. McMillian. 1983. Influence of resistant and susceptible corn silks on selected developmental parameters of corn earworm (Lepidoptera: Noctuidae) larvae. J. Econ. Entomol. 76(6):1288-1290, doi: 10.1093/jee/76.6.1288.

Wiseman, B.R., M.E. Snook, D.J. Isenhour, J.A. Mihm, and N.W. Widstrom. 1992. Relationship between growth of corn earworm and fall armyworm larvae (Lepidoptera: Noctuidae) and maysin concentration in corn silks. J. Econ. Entomol. 85(6):2473-2477, doi: 10.1093/jee/85.6.2473

Yadav, R.P. 1980. Response of sweet corn hybrids to corn earworm, Heliothis zea (Boddie) damage. Southern Univ. Res. Bul. 2(2):67-75. 